\title{
Sibling Relationships during Middle Adulthood in Uttarakhand and Haryana: A Comparative Study
}

\author{
Shourya Negi* and Shanti Balda
}

Department of Human Development and Family Studies, I.C. Collage of Home Science, CCS HAU Hisar - 125004, Haryana, India

*Corresponding author

\section{A B S T R A C T}

\section{Keywords}

Middle adulthood, Sibling relationship, Apathetic, Loyal, Congenial, Comparative study

Article Info

Accepted:

20 June 2019

Available Online:

10 July 2019
The comparative study was conducted purposively in Haryana and Uttarakhand states. Chamoli district from Uttarakhand and Bhiwani district from Haryana states were selected at random. From Chamoli block, Gair village and from Bhiwani block, Chang village was selected at random. Families with adults in the age range of 40-50 years were identified by snowball method. From each state urban and rural sample constituted of randomly selected 120 adults including 60 males and 60 females. The total sample constituted of 240 adults, 120 from Haryana and 120 from Uttarakhand (120 males and 120 females). Interview schedule was developed to obtain information on socio-personal variables. Adult Sibling Relationship scale by Nandwana and Katoch (2010) was used to assess sibling relationship of selected adults. Results revealed that majority of the adults from both the states had moderate level of contacts, emotional closeness, confiding and conflicts in relationships with their sibling. Regarding overall sibling relationship, majority of adults had loyal and congenial relationship with their siblings. There was no association between geographical location, area of residence, gender and overall sibling relationship. The findings have implications for adults in understanding relationship with their siblings during middle adulthood.

\section{Introduction}

Middle adulthood is the developmental period that begins at approximately 40 years of age and extends till 60-65 years of age. As described by Lachman (2004), middle adulthood involves balancing work and relationship responsibilities in the midst of the physical and psychological changes associated with aging. As people move from middle age to older adulthood, they often feel emotionally closer to their siblings and a majority of older adults consider one of their siblings to be their close friend.

The sibling relationship is one of the most enduring relationships throughout a person's life. Sibling relationships are the only close family relationships with the potential to last a lifetime. 
Ritttenour et al., (2007) reported that the sibling relationship is one in which a sibling is able to express emotions of loving and liking toward their sibling, while simultaneously engaging in aggressive behaviours, competition and rivalry.

Siblings share common biological and cultural heritage, as well as their childhood memories. Sibling relationships can vary as some siblings may have a relationship of long duration contacts, closeness and commitment, while others may have a purely formal relationship with little or no contacts or interest in one another. Siblings are very important in fostering an individual's development as it becomes more salient in later life and as a source of emotional support.

King (2007) mentioned that the relationship among siblings is one of the important aspects in a family system, where we can be the first friend of a child and have a lifelong relationship. Though sibling role is very prevalent throughout the life span of human being, and it is expected to be stable and emotionally close, very less research attention has been given to the relationships of siblings during adulthood. Generally the research on family relationship throughout adulthood typically focuses on the marital or parent-child dyads and very less importance is given to the role that kin play in development of an adult. Further the researches that have considered sibling relationship have restricted the scope of their work to children. These researchers have taken the psychological perspective, focusing on sibling rivalry and on the outcomes of personality as they are related to sibling possession, gender status, birth order and family size. But there is no direct attention given to the pattern of activities that keep siblings together throughout their life cycle.

During middle adulthood, the years between the age group of 40 to 60 years, a person actively gets involved with his or her family of procreation and economic endeavors. Middleaged adults are also known as sandwich generation because they get squeezed between taking care of their parents and meeting financial needs of their children. During this time when family and economic activities are on priority, siblings always play the role of friends and confidants. It is their general tendency to act as support for each other whenever situation demands and during times of crisis, which include help during illness, financial support and emotional support. Siblings act as pillars of support to deal with the stress that accompany caring for their parents or death of any family member. There is psychological or emotional support, that include feelings of security, comfort, companionship or giving advice or encouragement.

Keeping in mind the importance and the meaningfulness of the sibling relationship to the individual across the lifespan, we need to fill the gap in knowledge about the sibling relationship during the period of adulthood. Hence, the present study was planned to assess sibling relationships during middle adulthood in Haryana and Uttrakhand. The following hypotheses were framed:

Adults from Uttarakhand and Haryana states have loyal and congenial relationship with their siblings.

There is no association between location (Uttarakhand and Haryana) and overall sibling relationship of adults.

There is no association between area of residence (rural and urban) and overall sibling relationship of adults.

There is no association between gender of adults (male and female) and their overall sibling relationship. 


\section{Materials and Methods}

\section{Locale of the study and sample selection}

The comparative study was conducted purposively in Haryana and Uttarakhand states. Chamoli district from Uttarakhand and Bhiwani district from Haryana states were selected at random. From Chamoli district, Chamoli block was selected and from Bhiwani district, Bhiwani block was selected. From Chamoli block, Gair village and from Bhiwani block, Chang village was selected at random. Families with adults in the age range of 40-50 years were identified by snowball method.

Urban sample was taken from the selected block and rural sample was taken from the selected village. From both the places separate lists of male and female adults having at least one sibling was prepared by snowball method on their willingness to participate in the research study. From each state urban and rural sample constituted of randomly selected 120 adults including 60 males and 60 females. The total sample constituted of 240 adults, 120 from Haryana and 120 from Uttarakhand (120 males and 120 females). Mean age of adults from Haryana was 44.29 years and that of adults from Uttrakhand was 45.26 years. Mean age of male adults was 45.33 years and that of female was 44.23 years.

\section{Measures and method for data collection}

Interview schedule was developed to obtain information on socio-personal variables. Adult Sibling Relationship scale developed by Nandwana and Katoch (2010) was used to assess sibling relationship of selected adults. The scale has four dimensions i.e. Contact, Emotional closeness, Confiding and Conflict. It has 50 items, out of these 50 items, 22 are positive items and 28 are negative items. These dimensions are set on a 4-point scalealways (3), most of the time (2), sometimes
(1) and hardly ever (0) for positive items and scoring is reversed for the negative items.

\section{Results and Discussion}

\section{Sibling relationship among adults of Uttarakhand and Haryana}

Different dimensions of sibling relationship were categorized in three levels on the basis of their respective standard deviation - low (1 sd), moderate (in between -1 sd and +1 sd) and high $(+1 \mathrm{sd})$. Total scores were computed for overall sibling relationship and three levels were made on the basis of standard deviationapathetic (poor), loyal (average) and congenial (good). Results pertaining to sibling relationship among adults of Uttarakhand and Haryana have been presented in Table 1 .

As depicted in table, $67.5 \%$ adults from Uttarakhand and $65.8 \%$ adults from Haryana perceived moderate level of contacts with their siblings. Majority of adults from Uttarakhand (69.2\%) and Haryana (70.8 \%) perceived moderate level of emotional closeness with their siblings. Table further shows that majority of adults from Uttarakhand (68.3\%) and Haryana (65.0\%) had moderate level of confiding with their siblings. Further, the data shows that majority of adults $(60.8 \%$ from Uttarakhand and $63.3 \%$ from Haryana) perceived moderate level of conflicts with their siblings.

Data pertaining to overall sibling relationship revealed that equal percentage of adults from Uttarakhand and Haryana (40.8\%) perceived loyal (average) overall sibling relationship; 49.2\% adults from Uttarakhand and 43.4\% adults from Haryana perceived congenial (good) overall sibling relationship.

In the end it can be concluded that adults from both the geographical locations, that is, Uttarakhand and Haryana had loyal and 
congenial relationship with their siblings. Hence, the hypothesis that adults from Uttarakhand and Haryana states have loyal and congenial relationship with their siblings was accepted.

\section{Association between geographical location and sibling relationship}

Chi-square was computed between location of residence in Uttarakhand or Haryana states and overall sibling relationship of respondents. As displayed in Table 2 there was no significant association between location and overall sibling relationship of respondents, $\chi 2=2.02$ (d.f. $=2), p>0.05$. It can be interpreted from these results that overall sibling relationships of adult respondents from Uttarakhand and Haryana states were similar. Hence, the hypothesis that there is no significant association between location and overall sibling relationship of adults was accepted.

\section{Association between area of residence and sibling relationship}

Chi-square was also computed between area of residence (rural, urban) and overall sibling relationship of respondents. As presented in Table 3 that there was no significant association between area of residence and overall sibling relationship of respondents, $\chi 2=1.26$ (d.f. $=2), p>0.05$. It can be interpreted from these results that overall sibling relationships of urban and rural adult respondents were similar. Hence, the hypothesis that there is no significant association between area of residence and overall sibling relationship was accepted.

Association between gender and sibling relationship of respondents

Chi-square was also computed between gender of respondents and their overall sibling relationships. As shown in Table 4 there was no significant association between gender and sibling relationship of respondents, $\chi 2=0.98$ (d.f.=2), $\mathrm{p}>0.05$.

Lesser percentage of female respondents $(10.8 \%)$ had apathetic sibling relationship than their male counterparts $(15.0 \%)$. Taken together loyal and congenial relationship, percentage was greater for female adults $(89.2 \%)$ than their male counterparts $(85.0 \%)$.

It can be interpreted from these results that sibling relationships of male and female adult respondents were similar. Hence, the hypothesis that there is no significant association between gender of respondents and overall sibling relationship was accepted.

The results of the present study portrayed that majority of the adults from both the states, experienced moderate (average) level of contacts, emotional closeness, confiding and conflicts in their sibling relationships. Regarding overall sibling relationship, adults from both the states had loyal and congenial relationship with their siblings.

Hence, the hypothesis that adults from Uttarakhand and Haryana states have congenial and loyal relationship with their siblings is accepted. It can be interpreted from these results that during middle adulthood sibling relationships are very important in the life of individuals. The literature reviewed suggests that siblings at late life provide more social and psychological support and that dramatic increase in sibling exchange is seen in adults' life White (2001).The findings of the present study also get support from Kumari and Agarwal (2013). These authors conducted a study on the siblings in the age group of 4060 years and reported that majority of respondents were in average category of contacts, emotional closeness, confiding and conflict dimension of sibling relationships. 
Table.1 Sibling relationship among adults of Uttarakhand and Haryana

\begin{tabular}{|c|c|c|c|}
\hline $\begin{array}{l}\text { Dimensions } \\
\text { of sibling } \\
\text { relationship }\end{array}$ & Levels & $\begin{array}{l}\text { Uttarakhand } \\
\quad(\mathrm{n}=\mathbf{1 2 0})\end{array}$ & $\begin{array}{l}\text { Haryana } \\
(n=120)\end{array}$ \\
\hline \multirow[t]{3}{*}{ Contact } & Low (15and below) & $21(17.5)$ & $25(20.8)$ \\
\hline & Moderate (16 to 30$)$ & $81(67.5)$ & $79(65.8)$ \\
\hline & High (31 and above) & $18(15.0)$ & $16(13.4)$ \\
\hline \multirow{3}{*}{$\begin{array}{l}\text { Emotional } \\
\text { closeness }\end{array}$} & Low (16 and below) & $19(15.8)$ & $18(15.0)$ \\
\hline & Moderate (17 to 28$)$ & $83(69.2)$ & $85(70.8)$ \\
\hline & High (29 and above) & $18(15.0)$ & $17(14.2)$ \\
\hline \multirow[t]{3}{*}{ Confiding } & Low (11 and below) & $14(11.7)$ & $13(10.8)$ \\
\hline & Moderate (12 to 17 ) & $82(68.3)$ & $78(65.0)$ \\
\hline & High (18 and above) & $24(20.0)$ & $29(24.2)$ \\
\hline \multirow[t]{3}{*}{ Conflict } & Low (37 and above) & $22(18.4)$ & $27(22.5)$ \\
\hline & Moderate (20 to 36 ) & $73(60.8)$ & $76(63.3)$ \\
\hline & High (19 and below) & $25(20.8)$ & $17(14.2)$ \\
\hline \multirow{3}{*}{$\begin{array}{l}\text { Overall } \\
\text { sibling } \\
\text { relationship }\end{array}$} & Apathetic (Poor) (54-75) & $12(10.0)$ & $19(15.8)$ \\
\hline & Loyal (Average) (76-87) & $49(40.8)$ & $49(40.8)$ \\
\hline & Congenial (Good) (88-116) & $59(49.2)$ & $52(43.4)$ \\
\hline
\end{tabular}

Table.2 Association between geographical location and sibling relationship

\begin{tabular}{|c|c|c|c|c|}
\hline \multirow[t]{2}{*}{ Location } & \multicolumn{3}{|c|}{ Overall sibling relationship } & $\chi 2-$ \\
\hline & $\begin{array}{c}\text { Apathetic } \\
\text { (Poor) }\end{array}$ & $\begin{array}{c}\text { Loyal } \\
\text { (Average) }\end{array}$ & $\begin{array}{c}\text { Congenial } \\
\text { (Good) }\end{array}$ & \multirow[t]{3}{*}{2.02} \\
\hline Uttarakhand & $12(10.0)$ & $49(40.8)$ & $59(49.2)$ & \\
\hline Haryana & $19(15.8)$ & $49(40.8)$ & $52(43.3)$ & \\
\hline
\end{tabular}

Table.3 Association between area of residence and sibling relationship

\begin{tabular}{|l|c|c|c|l|}
\hline \multirow{2}{*}{ Area } & \multicolumn{3}{|c|}{ Overall sibling relationship } & $\begin{array}{l}\chi 2- \\
\text { value }\end{array}$ \\
\cline { 2 - 4 } & $\begin{array}{c}\text { Apathetic } \\
\text { (Poor) }\end{array}$ & $\begin{array}{c}\text { Loyal } \\
\text { (Average) }\end{array}$ & $\begin{array}{c}\text { Congenial } \\
\text { (Good) }\end{array}$ & 1.26 \\
\hline Urban & $16(13.3)$ & $50(41.7)$ & $54(45.0)$ & \\
\hline Rural & $15(12.5)$ & $48(40.0)$ & $57(47.5)$ & \\
\hline Note: Figures in parentheses indicate percentages & \\
\hline
\end{tabular}


Table.4 Association between gender and sibling relationship of respondents

\begin{tabular}{|l|c|c|c|c|}
\hline \multirow{2}{*}{ Gender } & \multicolumn{3}{|c|}{ Overall sibling relationship } & \multirow{2}{*}{ 2-value } \\
\cline { 2 - 4 } & $\begin{array}{c}\text { Apathetic } \\
\text { (Poor) }\end{array}$ & $\begin{array}{c}\text { Loyal } \\
\text { (Average) }\end{array}$ & $\begin{array}{c}\text { Congenial } \\
\text { (Good) }\end{array}$ & \multirow{2}{*}{0.98} \\
\hline Male & $18(15.0)$ & $47(39.2)$ & $55(45.8)$ & \\
\hline Female & $13(10.8)$ & $51(42.5)$ & $56(46.7)$ & \\
\hline Note: Figures in parentheses indicate percentages & \\
\hline
\end{tabular}

In another study Anwar (2010) reported that the meaning of late life centers on social relationships and caring for and being cared for by others. Sibling relationships are one of these relationships. Hence, it can be said that sibling relationships are crucial and important part of life.

On the basis of location (Uttarakhand, Haryana), area of residence (urban, rural) and gender of adults (male, female results further revealed that greater percentage of male and female adults had congenial relationship with their siblings followed by loyal and poor relationships. Hence, the hypotheses that there is no association between location and overall sibling relationship of adults; between area of residence and overall sibling relationship and between gender of respondents and overall sibling relationship were accepted.

It can be interpreted from these results that irrespective of geographical location, area of residence whether urban and rural, sibling relationship plays important role in an individual's life. It is worldwide known that sibling relationships are the most enduring relationships in everyone's lives.

Siblings share their family values, goals and knowledge with each other. They also share memories of their childhood, school and college. They also act as peers and share their secrets, ideas and experiences more often with each other than with their parents. Hence, siblings are unique family members throughout our life.
Although there was no significant association between gender and overall sibling relationships, however, when taken together loyal and congenial relationship, percentage was greater for female adults than their male counterparts.

The reason could be as explained in gender socialization theory that females are raised to manage emotions and relationships. So, they are better in managing social and kin relationships, particularly with their siblings. Another reason could be the gender difference in the content of conversation. Usually females share everything happening at home or workplace, but in case of males the conversation is limited to general well-being of siblings. In our Indian context, daughters have strong connections with their families and remain in contact to know the well-being of their aging parents who are living with their brothers.

These findings get support from the literature reviewed. Nandwana and Katoch (2009) reported that females are keen on maintaining family relationships. Dottan and Cohen (2011) accentuated that warmth between siblings is explained by gender with women feeling closer than men. Soysal (2016) also found significant difference in sibling relationship on the basis of gender. Bintory and Lakshmi (2017) revealed that female respondents were more inclined towards strengthening their relationship with siblings and keep in contact, while the male respondents were busy with fulfilling their 
responsibilities gave less importance to the sibling relationship.

In conclusion, irrespective of geographical location, majority of the adults experienced moderate level of contacts, emotional closeness, confiding and conflicts in their sibling relationships. Regarding overall sibling relationship, majority of adults had loyal and congenial relationship with their siblings. There was no association between geographical location, area of residence, gender and overall sibling relationship. Thus, it can be said that siblings are significant part of everyone's life and a special kind of figure to one another during adulthood. It is believed that siblings would support us in a crisis as siblings provide a sense of security during adulthood in our life.

\section{Acknowledgment}

The authors would like to thank the respondents who participated in this research and provided their valuable time. The authors acknowledge the infrastructure and support of CCS HAU, Hisar for carrying out this research.

\section{References}

Anwar, Y. (2010). Emotional intelligence peaks as we enter our 60s, research suggests. Retrieved from https://news.berkeley.edu/2010/12/16/agi ngemotion/ on 27.5.2019.

Bintory, R.R. and Lakshmi, H. (2017). Importance of sibling relationship during middle years. North Asian International Research Journal of Social Science \& Humanities, 3(6), 3-12.
Dottan, R.F. and Cohen, O. (2011). Young adult sibling relations: the effects of perceived parental favoritism and narcissism. The Journal of Psychology, 145(1), 1-22.

King, D. L. (2007). How Non-Disabled children respond to a sibling with disability? The challenges they may or may not have faced. M.Sc. Thesis. Smith College School for Social Work, Northampton, Massachusetts. Retrieved from https://scholarworks.smith.edu/cgi/viewco ntent.cgi article $=2414 \&$ context $=$ theses on 27.5.2019.

Kumari, B. and Agarwal, S. (2013). A study on sibling relationship in adulthood across gender. Advance Research Journal of Social Science, 4(1), 84-87.

Lachman, M. E. (2004). Development in midlife. Annual Review of Psychology, 55,305 .

Nandwana, S. and Katoch, M. (2009). Perception of sibling relationship during middle adulthood years: A typology. Journal of Social Sciences, 21, 67-72.

Nandwana, S. and Katoch, M. (2010). Manual for Adult Sibling Relationship Scale, National Psychological Corporation, Agra.

Rittenour, C. E., Myers, S. A., and Brann, M. (2007). Commitment and emotional closeness in the sibling relationship. Southern Communication Journal, 72(2), 169-183.

Soysal, F.S. (2016). A study on sibling relationships, life satisfaction and loneliness level of adolescents. Journal of Education and Training Studies, 4(4), 5867.

White, L. (2001). Sibling relationships over the life course: A panel analysis. Journal of Marriage and the Family, 63, 555-568.

\section{How to cite this article:}

Shourya Negi and Shanti Balda. 2019. Sibling Relationships during Middle Adulthood in Uttarakhand and Haryana: A Comparative Study. Int.J.Curr.Microbiol.App.Sci. 8(07): 2701-2707. doi: https://doi.org/10.20546/ijcmas.2019.807.331 